\title{
Adulto con Síndrome de Cimitarra y Defecto del Tabique Auricular Asociado a Hipertensión Pulmonar Multifactorial. Presentación de Caso.
}

Katherine T. Centeno Hurtado, Residente I Año Medicina Interna UIS Javier E. Fajardo Rivero, Médico Internista Neumólogo Stefano Valsangiacomo Avendaño, Médico General UDES Diego F. Garcia Bohórquez, Estudiante de Medicina UIS

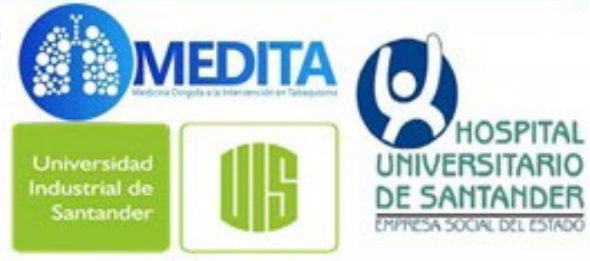

\section{Introducción}

El sindrome de Cimitarra (SC) es un defecto cardiaco congénito poco frecuente. Suele presentarse de forma aislada, no obstante, la malformación más frecuentemente asociada hasta en el $40 \%$ de los casos es la comunicación interauricular tipo OS, condición que pueden favorecer la aparición de HTP. La mayoría de los pacientes presentan sintomas durante la infancia temprana y necesitan una intervención quirúrgica rápida.

\section{Presentación del caso}

Hombre de 68 años de edad, con historia de Sindrome de Cimitarra, CIA e HTP diagnosticados a los 43 años de edad, corrección del DTA, sin tratamiento posterior, asintomático durante 20 años. Deterioro de clase funcional en el año 2013 con diagnóstico en el seguimiento de falla cardiaca izquierda FEVIp, FA y EPOC Gold D, en manejo con IECA + B.bloqueador, Warfarina, LAMA + ICS, respectivamente, adicionalmente Bosentan durante el último año. Quien consulta en la actualidad por deterioro de la clase funcional, infecciones respiratorias inferiores recurrentes y TEP de diagnóstico reciente. Al examen físico con signos de dificultad respiratoria, requerimiento de oxígeno a bajo flujo, signos de derrame pleural derecho, hepatomegalia, edema de MMII y pigmentación ocre de la piel. Último Cateterismo derecho con PAPm, $55 \mathrm{mmHg}$, PFDVI: $30 \mathrm{mmHg}$, RVP:5 Woods, Test de vasorreactividad (-), comunicación interauricular tipo seno venoso inferior con shunt izquierda a derecha. ECOTT con disfunción diastólica tipo I. Espirometría obstructiva grave y DLCO2 disminuida.

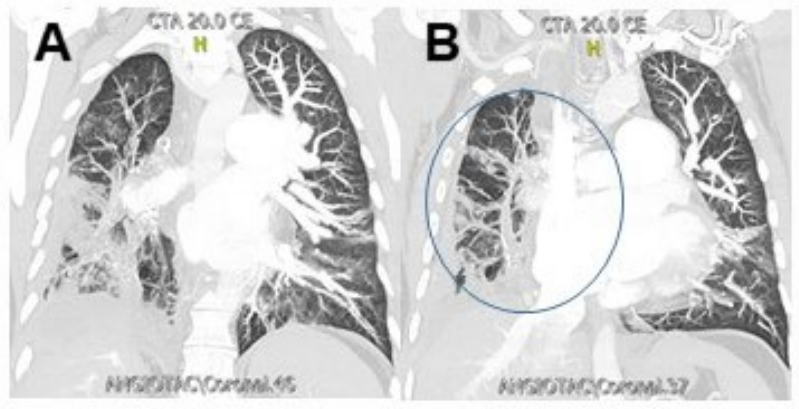

Figuras A y B. Cortes coronales.

A. Se muestra un pulmón derecho con reducción de su tamaño, cambios fibrocicatrizales hacia la base con derrame pleural adyacente.

B. Se observa drenaje venoso anómalo del pulmón derecho a la vena cava inferior

\section{Discusión}

La incidencia del SC se calcula en 1 a 3 casos por 1.000 .000 nacidos vivos, siendo más frecuente en mujeres (relación 2:1). Aproximadamente el $70 \%$ de los pacientes son diagnosticados antes de los diez años. La existencia de HTP es el factor pronóstico más importante. Su presencia puede estar relacionada con una CPC coexistente como una $\mathrm{CIA}$, en un paciente con múltiples causas adicionales de HTP.

\section{Conclusiones}

Resulta extremadamente inusual que formas combinadas de cardiopatias complejas sean diagnosticadas a una edad tan tardia especialmente en la presencia de HTP en un paciente con comorbilidades asociadas que configuran entidades responsables de HP de 4 de los 5 grupos descritos.

Referencias

Referencias 1 Opotowsky Alexander R, Webb Gary D. A battle in the crusade to understand scimitar syndrome. European Heart Journal. 2017; 0, 1-3.2) Wang Hanjay, Kalfa David,

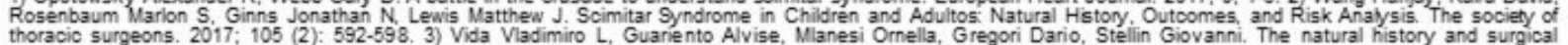
thoracic surgeons. $2017 ; 105$ (2): 592-598. 3) Vida Vladimiro L. Guariento Alvise, Mlanesi Ornella, Gregori Dario, Stelin 